\title{
MUTANT EXPRESSION IN DIPLOID POTATOES
}

\author{
N. W. SIMMONDS \\ John Innes institute, Hertford
}

Received 28.ix.64

\section{INTRODUCTION}

There is, in the Andes of South America, a great diversity of diploid cultivated potatoes. Like their wild ancestors, they have an oppositional $(S)$ allele mating system and their populations carry many deleterious recessive genes floating in the heterozygous phase (Dodds and Paxman, 1962). The biochemistry of certain classes of mutant expression is now becoming well understood in micro-organisms but has yet been little studied in higher plants. This paper reports general botanical studies of diploid potato mutants as a preliminary to possible biochemical study; and two attempts to detect, by screening procedures, auxotrophic mutants.

\section{MATERIALS AND METHODS}

All plant materials used came from the Commonwealth Potato Collection (C.P.C.). Names of the diploid cultivar groups are abbreviated where necessary as follows (see Dodds and Paxman, 1962, for classification):Stn-Stenotomum Group, Phu-Phureja. The mutants used and their origins are given in table $\mathrm{I}$. The seed bulks used in searching for auxotrophic mutants all came from openpollinated seed of mixed plantings of various cultivated diploids grown out of doors.

Nutrient sprays were based on the culture solutions used by Langridge (1958). Three stock solutions were made up, mixed in equal volumes and diluted tenfold for use: (I) amino acids-I per cent. casein hydrolysate; (2) nucleic acids-I gm. sodium salt of yeast nucleic acid hydrolysed in $20 \mathrm{ml}$. $0 . \mathrm{I} \mathrm{N} \mathrm{NaOH}$ at $50^{\circ} \mathrm{C}$. for 30 mins., neutralised with $\mathrm{HCl}$ and made up to $120 \mathrm{ml}$; ; (3) vitamins--thiamin $\mathrm{HCl} 200$ p.p.m., riboflavin 200 p.p.m., nicotinic acid 1000 p.p.m., CaD-pantothenate 200 p.p.m., pyridoxine $\mathrm{HCl} 200$ p.p.m., D-biotin 10 p.p.m., $i$-inositol 4 per cent., folic acid 200 p.p.m., ascorbic acid 0.4 per cent., choline chloride 200 p.p.m., p-aminobenzoic acid Ioo p.p.m.

\section{RESULTS}

\section{(i) Mutants and genetic results}

The twelve mutants studied are listed in table 1 . The genetics of three, $y m, n l$ and $s l$ have been described by Dodds and Paxman (1962); four others ( $v c, p y, h d$ and $c r$ ) were detected by Dr G. J. Paxman and will be treated elsewhere; and genetic results for the remaining six are given in table 2 (in large part unpublished observations by $\operatorname{Dr} \mathrm{K}$. S. Dodds).

The suggestively large linkage $\chi^{2}$ for $y m d x$ is probably meaningless since neither single-gene ratio was very good and linkage can be, at most, very slight. The disturbed ratios caused by linkage of $d r$ to the $S$ locus will be discussed elsewhere. 
TABLE I

Recessive mutants of diploid potatoes

\begin{tabular}{|c|c|c|}
\hline Symbol & Name & Description, etc. \\
\hline$y m$ & yellow margin & $\begin{array}{l}\text { Plants stunted, leaflets small, rounded, with yellow } \\
\text { margins. Frequent in Phureja Group (Dodds and } \\
\text { Paxman, 1962). 'Two tetraploid clones from Andigena } \\
\text { Group also used. }\end{array}$ \\
\hline$n l$ & narrow leaflet & $\begin{array}{l}\text { Plants fairly vigorous, leaflets narrow. Frequent in } \\
\text { Phureja Group (Dodds and Paxman, r962). }\end{array}$ \\
\hline$l r$ & leaf roll & $\begin{array}{l}\text { Plants stunted, stems thin, numerous, leaves rolled } \\
\text { upwards, tinged purple below, brittle; very similar } \\
\text { in appearance to infection by Leaf-roll virus. Source } \\
\text {-Phu I } 3 \text { III. }^{\text {P }}\end{array}$ \\
\hline$d x$ & defective xylem & $\begin{array}{l}\text { Plants stunted, sometimes lethal, leaves small, soft, } \\
\text { leaflets rounded, stems rather thick and brittle, xylem } \\
\text { abnormal (see below); stems (especially in young } \\
\text { seedlings) sometimes go through a transient phase in } \\
\text { which leaf segments become pale, ultimately white- } \\
\text { necrotic and much reduced, the tip dies and normal } \\
\text { growth is carried on by a lateral. Expression } \\
\text { remarkably variable even within a single clone. } \\
\text { Source-Phu } 1776,2203 \text { and } 2205 \text {. }\end{array}$ \\
\hline$c l$ & curled leaf & $\begin{array}{l}\text { Plants stunted, lateral leaflets much reduced, often } \\
\text { absent, terminals lanceolate tending to curl down- } \\
\text { wards longitudinally, often tinged with purple when } \\
\text { young, especially at the base, later at the distal } \\
\text { margins. Source-Phu } 217 \mathrm{I} \text { and } 235^{8} \text {. }\end{array}$ \\
\hline sh & shorty & $\begin{array}{l}\text { Vigorous dwarf with short internodes and short cells } \\
\text { (see below). Source- }-\operatorname{Stn} 1856 \text {. }\end{array}$ \\
\hline$v c$ & veinal chlorosis & $\begin{array}{l}\text { Plant fairly vigorous, chlorotic, mainly along the } \\
\text { veins. Source-clones of Subgroup Goniocalyx } \\
\text { (Paxman, unpubl.). }\end{array}$ \\
\hline$p y$ & pink and yellow & $\begin{array}{l}\text { Plant stunted, similar to } y m \text { in phenotype but leaflets } \\
\text { pointed, pink underneath. Source-polyhaploid } \\
\text { Andigena stock (Paxman, unpubl.). }\end{array}$ \\
\hline hd & hairy dwarf & $\begin{array}{l}\text { Plant stunted with many thin wiry stems, densely } \\
\text { hairy, small rounded leaflets. Source-Stn } 1802 \\
\text { (Paxman, unpubl.). }\end{array}$ \\
\hline al & albino & White seedling lethal. Source-Stn 1856 . \\
\hline$c r$ & crumpled & $\begin{array}{l}\text { Plant very stunted, stems contorted, leaves crumpled, } \\
\text { blotchy-streaky chlorotic. Source-Phu i } 776 \text { (Pax- } \\
\text { man, unpubl.). }\end{array}$ \\
\hline$d r$ & droopy & $\begin{array}{l}\text { Plant fairly vigorous, tall and slim, leaves reduced, } \\
\text { tends to wilt badly leading to tip-scorch and pre- } \\
\text { mature abscission (see below). Source-Phu } 2862 \\
\text { and } 2863 \text {. }\end{array}$ \\
\hline
\end{tabular}


(ii) Physiological and morphological studies

The possibility that one or more of the twelve mutants was deficient for a relatively simple mobile metabolite was tested by two means. First, weekly nutrient sprays containing amino acids, vitamins and nucleic acids (see above) were applied and general growth and appearance compared with controls. Had a response been obtained, the spray would have been fractionated in order to determine the specific nutrient concerned. In a few cases in which phenotype suggested mineral deficiency, mineral sprays were also applied, e.g. ferric EDTA to $v c$. Second, grafts were made, always in the direction normal stock plus mutant scion and sometimes in the reverse direction as well. An exception was al which died in the cotyledon stage, too young to graft. No response to any spraying or grafting treatment was obtained (plate, D, E).

TABLE 2

$F_{2}$ segregations in diploid potatoes

\begin{tabular}{|c|c|c|c|c|}
\hline \multirow{2}{*}{$\begin{array}{l}\text { Locus } \\
\text { (notes) }\end{array}$} & \multirow{2}{*}{ Normal } & \multirow{2}{*}{ Mutant } & \multicolumn{2}{|c|}{$\chi^{2}$ (d.f.) } \\
\hline & & & Dev. & Het. \\
\hline $\begin{array}{l}d x^{*} \\
c l \dagger \\
l r_{\ddagger}^{+} \\
s h \\
a l \\
d r \S\end{array}$ & $\begin{array}{r}548 \\
88 \\
139 \\
136 \\
464 \\
128\end{array}$ & $\begin{array}{r}204 \\
43 \\
36 \\
55 \\
167 \\
67\end{array}$ & $\begin{array}{l}\mathrm{I} \cdot 82 \text { (I) } \\
4 \cdot 28 \text { (I) } \\
\mathrm{I} \cdot 83 \text { (I) } \\
\mathrm{I} \cdot 47 \text { (I) } \\
0 \cdot 72 \text { (I) } \\
9 \cdot 1 \mathrm{I} \text { (I) }\end{array}$ & $\begin{array}{c}9.94(6) \\
\ldots \\
0.36(1) \\
\ldots \\
0.97(3) \\
\ldots\end{array}$ \\
\hline
\end{tabular}

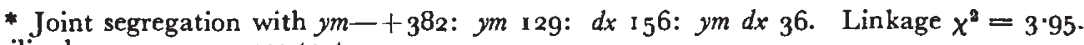
families homogeneous; see text.

† Joint segregation with $y m-+66: y m$ 22: $c l 34: y m c l$ 9. No linkage.

\$ Joint segregation with $n l-+50: n_{1}{ }_{5}: \operatorname{lr} 12: n l$ lr 7 . No linkage.

$\S$ Disturbed ratio caused by linkage to $S$ locus.

Four mutants were subjected to further study. They were $l r, d x$, $s h$ and $d r$ and the results were as follows.

1. Anatomy of leaf roll $(l r)$. The phenotypic similarity between this mutant and a potato infected by leaf roll virus at once suggests a defect of the phloem. Virus infected plants are known to accumulate starch in their leaves and to show a phloem necrosis of which two histological correlates are a pseudo-lignification of the cells and formation of callose plugs (review in Bode, i962). The mutant accumulated starch, as shown by decolorisation and iodine-staining of detached leaflets but no gross anatomical defect of the phloem (e.g. absence or reduction in amount, cell distortion or lignification) could be found. A defect of fine structure or of function is not thereby excluded and the need for physiological study of function by tracer techniques is clearly indicated.

2. Anatomy of defective xylem $(d x)$. Unlike the preceding, this mutant does present a picture of gross anatomical disturbance 
(plate, A-C). The vessels/tracheids of the xylem are of irregular appearance in cross-section and are even, especially in the protoxylem, quite collapsed; those nearest the cambium are most nearly regular in appearance so the malformation seems to reflect a failure to maintain normal shape against the pressures of surrounding cells, rather than an initial failure of expansion.

3. The expression of shorty $(s h)$. This mutant is usually well expressed in the young seedling stage; it is shorter and appears more sturdy than the normals. Height measurements (soil to growing point) classify it with little ambiguity (table 3 ).

TABLE 3

Heights of seedlings in a family segregating shortly

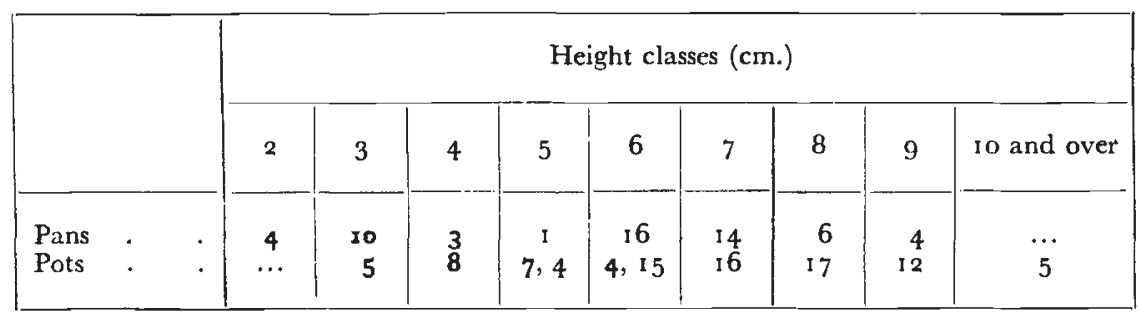

Note-All plants the same age, though some crowded in pans, others separated in pots; plants classified sh sh in bold face.

After 4 or 5 weeks' growth, mutant and normal seedlings weigh about the same and bear the same number of nodes and the difference in height is therefore due to internode elongation. Thus mean internode lengths were $(5$ seedlings each, mean number of internodes $>\mathrm{I} \mathrm{mm}$. long 8.8 in each group): shorty $-5.5 \mathrm{~mm}$., normal $-9.8 \mathrm{~mm}$. Later still, when the plants are in full flower, the proximal internodes are longer than in the seedling and the difference is, if anything, enhanced, e.g. :

\begin{tabular}{|c|c|c|c|c|}
\hline & \multicolumn{3}{|c|}{$\begin{array}{l}\text { Mean length (mm.) of } \\
\text { internodes numbered }\end{array}$} & \multirow[t]{2}{*}{$\begin{array}{l}\text { Plant } \\
\text { height }(\mathrm{cm} .)\end{array}$} \\
\hline & $I-5$ & $6-10$ & $\mathrm{II}-\mathrm{I} 5$ & \\
\hline $\begin{array}{l}\text { Normal } \\
\text { Shorty }\end{array}$ & $\begin{array}{r}14 \\
5\end{array}$ & $\begin{array}{l}38 \\
\text { II }\end{array}$ & $\begin{array}{l}65 \\
18\end{array}$ & $\begin{array}{r}104 \\
4 \mathrm{I}\end{array}$ \\
\hline
\end{tabular}

The number of the node that bears the first flower is similar; thus, for two separate sets of observations: shorty-node number 17.4 and 17.7 , normal-15.3 and $19 \cdot 0$. During subsequent growth the impression is that shorty is more branched and bushy and this was (somewhat erratically) borne out by measurements which also made it clear that total growth of ærial parts and tubers in normal and shorty were very similar. On balance, therefore, shorty seems to be not at all deleterious. 
Cell lengths in the middles of stem internodes were measured in longitudinal sections of cortex and pith in samples taken from the base, the middle and the top of representative stems up to the first flowering node. The following figures are mean cell lengths (microns), each entry based on 80 observations (four replicate stems $\times$ cortex and pith $\times$ Io measurements from each sample:

\begin{tabular}{|c|c|c|c|}
\hline & Bottom & Middle & Top \\
\hline Normal & I 79 & 142 & 133 \\
\hline Shorty. & 104 & 122 & II 2 \\
\hline
\end{tabular}

The LSD between any two entries is $23 \mu$ so it is evident that normal cells are longer than those of shorty and that the difference is greatest in the base of the plant. On average, normal cells are 134 per cent. of those of shorty, in only fair agreement with gross internode measurements (above). Cell elongation therefore accounts for some but not all of the difference between genotypes.

The phenotype of shorty suggests a genetic gibberellin-deficiency of the kind known in maize, peas and barley. Spraying experiments lend (somewhat ambiguous) support to the idea. Thus a total of six sprays at 250 p.p.m. spread over 6 weeks of early growth caused marked internode elongation in shorty and produced plants that approximated in general appearance to normal; but normals also responded to sprays at least as strongly as the mutant. It will be noted that fairly heavy repeated doses were required to produce a sustained response.

Trials with six other gibberellins indicated that all were active. It was not possible to do cxtensive replicated tests and there were several anomalics as between different trials: with these qualifications, the indications were that $A_{8}$ and $A_{9}$ were least active, $A_{1}$ and $A_{5}$ more so and $\mathrm{A}_{4}$ and $\mathrm{A}_{7}$ most active. A rather curious subsidiary result comes from an experiment in which $A_{4}$ and $A_{7}$ were applied (three sprays, 200 p.p.m., at weekly intervals) to young seedlings. The order of response was $A_{7}>A_{4}>$ controls for both normal and shorty; measurements showed that shorty responded strongly in cell length but that normals did not, though they undoubtedly responded in total growth.

Conclusions are that shorty differs from normal primarily in internode elongation and that this itself is partly a reflection of cell length; that the shorty phenotype can be "corrected" by relatively heavy gibberellic acid sprays; and that, since normals respond at least as strongly as the mutant, it is hard to regard shorty as a simple gibberellin-deficient type. In its spectrum of response to a range of different gibberellins, shorty most resembled the Meteor pea of the eight test organisms used by Brian et al. (1964). 
4. The expression of droopy $(d r)$. Droopy plants are about 40 per cent. taller and also slimmer than normals from an early stage in growth but the main difference lies in physiological behaviour. The mutant was first recognised as a plant which wilted uncontrollably in the glasshouse in warm weather; and, though it recovered during the night, prolonged wilting resulted in tip scorching and premature leaf dropping. Grafts showed that the defect did not lie in the roots or vascular system since droopy stocks supported vigorous normal scions and droopy wilted on a normal stock. Experiments with excised leaves showed that droopy lost water more rapidly than normal and observations of stomata showed that the under-surfaces of droopy leaves bore about I 4 times as many stomata per unit area as normal. The plant is clearly of physiological interest and quantitative studies of its behaviour are in progress (Waggoner, unpub.). It resembles Rick's (1952) wilty dwarf (wd) mutant of tomato in its wiltiness, slimmer stems and smaller leaves but differs in many other respects including behaviour (especially response to grafting).

\section{(iii) A search for auxotrophic mutonts}

The results reported above indicate that none of the known recessive mutants tested could be corrected by grafting or by the application of sprays containing various essential metabolites for which genetical deficiency might be expected. There are, however, in diploid potatoes, many weak segregates which grow slowly and die young; some may be simple recessives yet unrecognised, others are probably weak recombinants arising from inbreeding. On the possibility that auxotrophic mutants (or, at least, correctable nutritional deficients) occurred among them, two screening experiments were carried out.

In the first experiment, 20,000 diploid seeds of various origins were sown and all vigorous seedlings discarded. The $\mathrm{I} 300$ survivors were sprayed weekly and all the chlorotic plants (I I 2) were potted, together with 50 extreme weaklings and 50 of the better (but still weak) seedlings; there were many losses and only $7 \mathrm{I}$ plants survived to produce tubers. These were grown in duplicate, one control and one sprayed, but there was no sign of response.

The second experiment made use of the fact that seed size is correlated with seedling vigour: very small seeds tend to produce weaklings. On the assumption, as above, that the weak seedling fraction might be expected to contain the nutritional deficients, three bulks of potato seeds were sieved and the fractions passing a $\mathrm{I} \mathrm{mm}$. (round mesh) sieve were used. Approximately I 700 seeds were obtained, representing just under I per cent. of the original population. Germination was, as expected, poor ( $5^{8}$ per cent.) and many ( 170 ) of the 984 seedlings that were potted died in a few weeks. Spraying was done twice weekly, beginning as soon as germination started. Eighty recognisable recessive mutants were discarded, together with $5^{19}$ vigorous plants, leaving $2 \mathrm{I} 5$ viable weaklings for further study. Of these, 

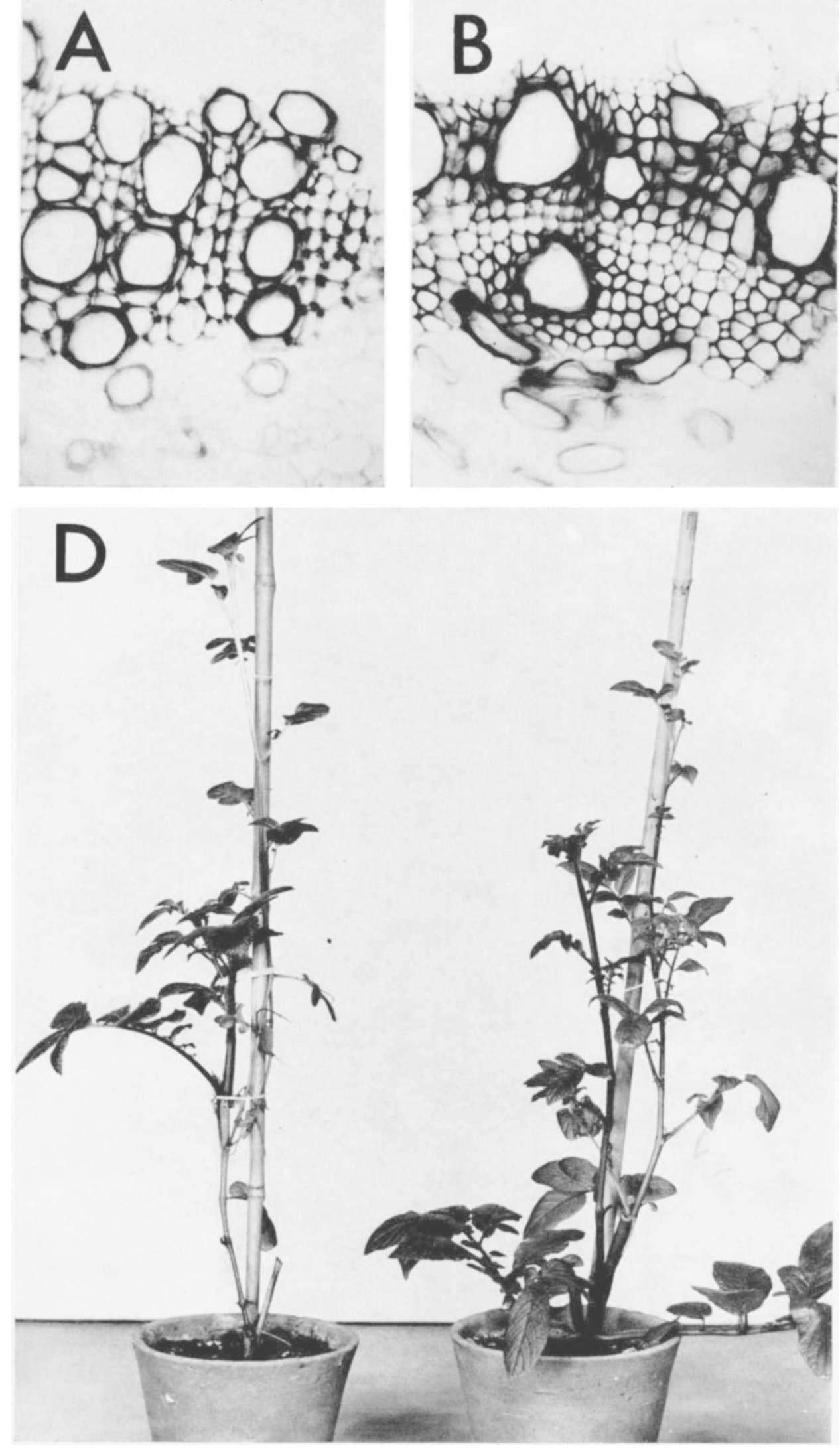


\section{Plate}

A, B, C.-Anatomy of defective xylem (transverse sections of xylem). A normal, B and C $d x$; $A$ and B primary bundles from young stems $\left(\times 33^{\circ}\right) ; C$ older bundle after much secondary thichening $\left(X_{150}\right)$.

D.-Reciprocal grafts of normal and droopy. On left $d r$ stock plus normal scion, on right reciprocal.

E.-Leaf roll mutant scion (shoot above) grafted on normal stock (shoot below). 


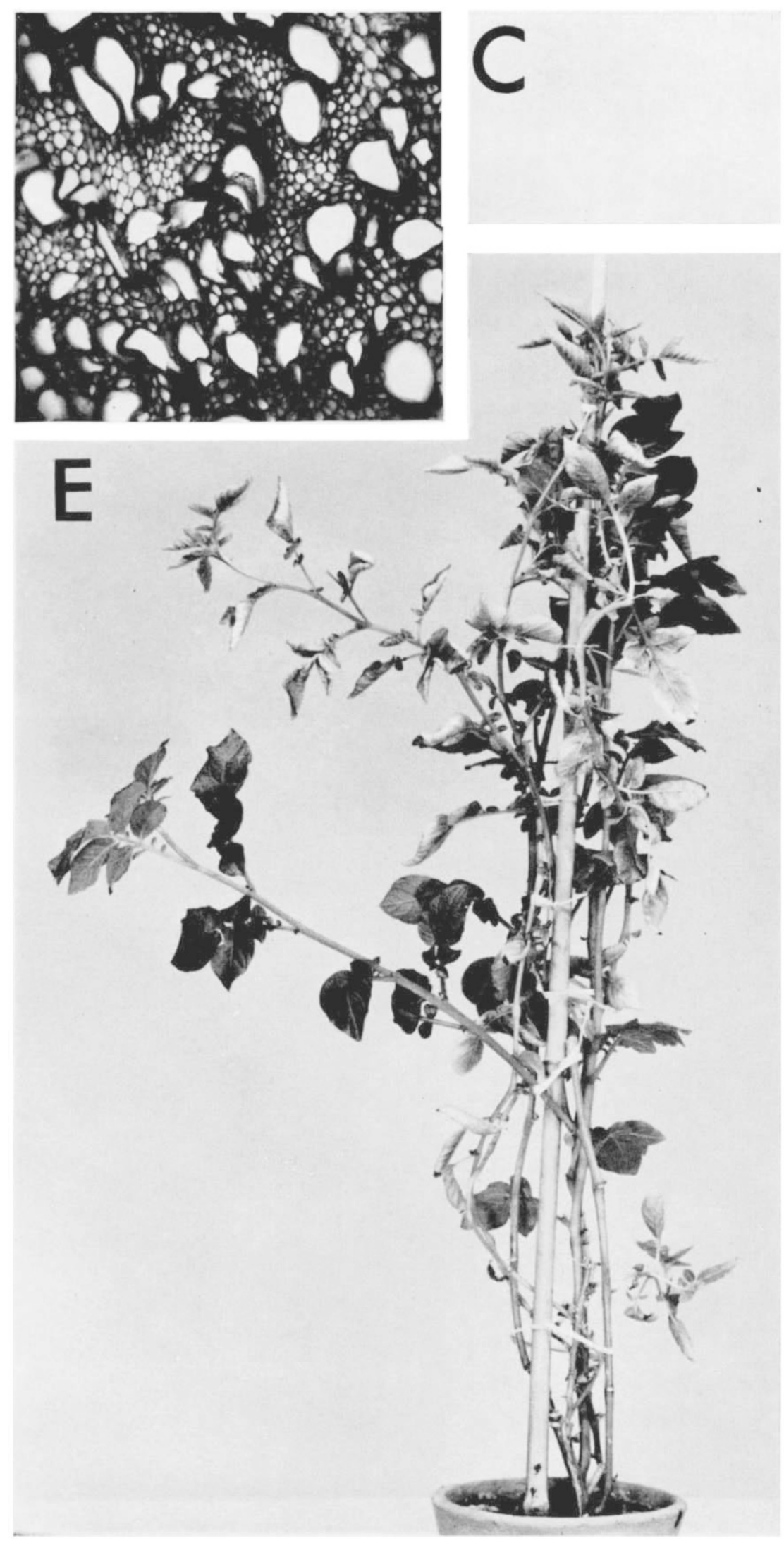


I 93 were propagated by cuttings and used for a spraying/no spraying trial. Four gave weak indications of response to spraying and these were further propagated and tested: none could be confirmed as responding to the treatment.

\section{DISCUSSION}

Few cases of mutants that control simple metabolic defects in higher plants are known: cysteine and vitamin deficiencies in Arabidopsis (Langridge, I958; Rédei, I96o, I962, I963); thiaminedeficiency in tomato (Langridge and Brock, I96I); some more complex requirements in Arabidopsis (Langridge, I958) and tomatoes (Mackinney, Rick and Jenkins, I956; Mathan and Jenkins, I962); disturbance of iron metabolism in soybeans (Weiss, I943; Brown et al., I958) and in maize (Bell et al., I 962); disturbance of magnesium metabolism in celery (Pope et al., I952); and various gibberellin deficiencies in maize, peas and barley (reviews in Brian, I 959; Pelton, 1964). The rarity of such mutants may, however, be more apparent than real, for Langridge (1958) found that two out of I 6 seedling lethals tested represented simple remediable metabolic defects: in Neurospora, Atwood and Mukai (1953) found that two out of 26 natural lethal mutants fell in the same category. Presumably, intensive search of higher plant material-especially of a technically favourable organism such as Arabidopsis-will eventually reveal the same sort of spectrum of metabolic defects that is already well known in Neurospora.

Langridge studied seedling lethals on the grounds that deficiency of a mobile essential metabolite would be expected to have this expression. The argument, however, ignores "leakiness" and "leaky " mutants are certainly frequent in Neurospora (though just how frequent seems to be unrecorded). The screening experiments with potatoes described here were undertaken on the assumption that "leaky" would be more common than complete defects and that they should be revealed by weak growth rather than lethality. This argument seems particularly relevant to an outbreeder such as the diploid potato in which variability of the genetic background causes wide variation in the expression of morphological mutants segregating in a single family. Failure to detect auxotrophic mutants in these experiments therefore can hardly mean that they are not there; some may have been missed, due to the necessarily rather crude techniques employed, or uptake may have limited response in others but, more probably, the weaklings selected for test were the products of general inbreeding depression rather than recessives suffering from unitary metabolic defects.

Acknowledgments.-Thanks are due to $\operatorname{Dr} \mathrm{K}$. S. Dodds for permission to quote unpublished genetic data and for many valuable observations on certain mutants; to Dr P. W. Brian and Messrs I.C.I. for the provision of gibberellins; to Dr P. Waggoner for helpful suggestions on the droopy mutant; and to $\mathrm{Mr} \mathrm{D}$. Cutler for observations on the anatomy of the leaf roll mutant. 


\section{SUMMARY}

Twelve naturally-occurring recessive mutants of cultivated potatoes were studied; spraying and grafting treatments gave no evidence that any of them suffered from a simply remediable metabolic defect. Attempts to detect auxotrophic mutants by screening procedures were unsuccessful. Anatomical and physiological observations of four mutants are reported.

\section{REFERENCES}

ATWOOD, K. C., AND MUKAI, K. C. I953. Indispensable gene functions in Neurospora. Proc. nat. Acad. Sci., Wash., 39, $1027-1035$.

BELL, W. D., BOGORAD, L., AND MCILRAT, W. J. I962. Yellow-stripe phenotype in maize. I. Effects of $y s_{1}$ locus on uptake and utilization of iron. Bot. Gaz., 124, I -8 .

BoDE, o. 1962. Die Blattrollkrankheit der Kartoffel. Angew. Bot., 30, 86-i 16.

BRIAN, P. W. 1959. Effects of gibberellins on plant growth and development. Biol. Rev., 34, 37-84.

BRIAN, P. W., HEMming, H. G., AND LoWE, D. I 964 . Comparative potency of nine gibberellins. Ann. Bot., Lond., 28, 369-399.

BROWN, J. B., HOLMES, R. S., AND TIFFIN, L. O. I958. Iron chlorosis in soybeans as related to the genotype of rootstock. Soil Sci., 86, 75-82.

DODDS, K. S., AND PAXMAN, G. J. I962. The genetic system of cultivated diploid potatoes. Evolution, 16, I 54-167.

LANGRIDGE, J. 1958. A hypothesis of developmental selection exemplified by lethal and semi-lethal mutants of Arabidopsis. Aust. 7. biol. Sci., $11,58-58$.

LANGRIDGE, J., AND BROCK, R. D. I961. A thiamine requiring mutant of the tomato. Aust. 7. biol. Sci., 14, 66-69.

MAGKINNEY, G., RICK, C. M., AND JENKINS, J. A. 1956. The phytoene content of tomatoes. Proc. nat. Acad. Sci., Wash., 42, 404-408.

MATHAN, D. S., AND JENKINS, J. A. 1962. A morphogenetic study of lanceolate, a leaf shape mutant in the tomato. Amer. 7. Bot., 49, 504-514.

pelton, J. s. 1964. Genetic and morphogenetic studies of Angiosperm single-gene dwarfs. Bot. Rev., 3o, 479-512.

POPE, D. T., MUNGER, H. M., AND CAREW, J. 1952. Chlorosis in celery, an inherited magnesium deficiency. N.Y. agr. Exp. Sta. Farm Res., 18/1, 10.

RÉDEI, G. P. I960. Genetic control of 2,5-dimethyl-4-aminopyrimidine requirement in Arabidopsis thaliana. Genetics, 45, 1007.

RÉDEI, G. P. I962. Genetic block of vitamin thiazole synthesis in Arabidopsis. Genetics, 47, 979 .

RÉDEI, G. P. I 963 . Somatic instability caused by a cysteine-sensitive gene in Arabidopsis. Science, 139, 767-769.

RICK, С. м. 1952. The grafting relations of wilty dwarf, a new tomato mutant. Amer. Nat., 86, I73-184.

WEISS, M. G. I943. Inheritance and physiology of efficiency in iron utilization in Soybeans. Genetics, 28, 253-268. 